\title{
PARTICULARIDADES DA EDUCAÇÃO FÍSICA NA PRÉ-ESCOLA EM TRÊS MUNICÍPIOS DA REGIÃO DO GRANDE ABC PAULISTA
}

\author{
PARTICULARITIES OF PHYSICAL EDUCATION IN THE \\ PRE-SCHOOL IN THREE MUNICIPALITIES IN THE GREATER \\ SÃO PAULO ABC REGION.
}

\begin{abstract}
PARTICULARIDADES DE LA EDUCACIÓN FÍSICA EN LA PRE-ESCUELA EN TRES MUNICIPIOS DE LA REGIÓN DEL GRAN ABC PAULISTA
\end{abstract}

\author{
Alex Moura Sobrinho ${ }^{\mathrm{I}}$ \\ Paulo Sergio Garcia ${ }^{\text {II }}$ \\ 'Universidade Municipal de São Caetano do Sul (USCS), \\ São Caetano do Sul/SP-Brasil \\ "Universidade Municipal de São Caetano do Sul (USCS), \\ São Caetano do Sul/SP-Brasil
}

\begin{abstract}
Resumo A Educação Infantil constitui-se em um nível de ensino de extrema relevância para o desenvolvimento integral das crianças. É nessa etapa que elas podem vivenciar o maior número possível de experiências e, neste contexto, a Educação Física é fundamental. Todavia, essa disciplina apresenta grande variedade de propostas educacionais e pedagógicas. Este estudo analisa a percepção de diretoras sobre os desafios e as dificuldades da prática de Educação Física na pré-escola, para o atendimento às crianças, em três municípios da região do Grande ABC. Para atender ao objetivo foi utilizada a metodologia qualitativa, a partir da análise de documentos e de entrevistas semiestruturadas com diretoras de escolas. Os resultados revelaram preocupações e zelo das autoridades políticas e educacionais a partir da presença de diretrizes curriculares, que orientavam o trabalho dos professores, e de argumentações sólidas das diretoras quanto à importância da Educação Física. Todavia, também foram encontrados elementos de descaso em relação à formação do professor que ministra a aula e no que se refere à infraestrutura escolar. Os dados deste estudo podem ser utilizados no contexto da formação inicial e contínua de professores e, ao mesmo tempo, pelas secretarias de educação dos municípios brasileiros.
\end{abstract}

Palavras-chave: Educação Física; Pré-Escola; Gestão Pedagógica da Escola. 
ABSTRaCr Early childhood education is an extremely important level of education for the integral development of children. It is at this stage that they can experience as many experiences as possible and, in this context, Physical Education is fundamental. However, this discipline presents a wide variety of educational and pedagogical proposals. This study analyzes the perception of principals about the challenges and difficulties of preschool Physical Education practice for the care of children in three municipalities of the Greater $\mathrm{ABC}$ region. To meet the objective, the qualitative methodology was used, based on document analysis and semi-structured interviews with school principals. The results revealed concerns and zeal from the political and educational authorities as from the presence of curricular guidelines that guided the teacher's work, and solid arguments from the principals about the importance of Physical Education. However, there were also elements of neglect regarding the teacher's education who teaches the class and the school infrastructure. The data from this study can be used in preservice and in-service education and, at the same time, by the education departments of the Brazilian municipalities.

Keywords: Physical Education; Early Childhood Education; Educational AdminISTRATORS.

Resumen La educación de la primera infancia es un nivel educativo extremadamente relevante para el desarrollo integral de los niños. Es en esta etapa que pueden experimentar tantas experiencias como sea posible y, en este contexto, la educación física es fundamental. Sin embargo, esta disciplina presenta una amplia variedad de propuestas educativas y pedagógicas. Este estudio analiza la percepción de los directores sobre los desafíos y dificultades de la práctica de educación física preescolar para el cuidado de niños en tres municipios de la región del Gran ABC. Para cumplir el objetivo, se utilizó la metodología cualitativa, basada en análisis de documentos y entrevistas semiestructuradas con directores de escuelas. Los resultados revelaron inquietudes y entusiasmo de las autoridades políticas y educativas por la presencia de pautas curriculares que guiaron el trabajo de los docentes y argumentos sólidos de los directores sobre la importancia de la educación física. Sin embargo, también hubo elementos de negligencia con respecto a la capacitación del maestro que enseña la clase y la infraestructura escolar. Los datos de este estudio pueden ser utilizados en el contexto de la formación inicial y continua del profesorado y, al mismo tiempo, por los departamentos de educación de los municipios brasileños.

Palabras clave: Educación Física; Educación de la Primera Infancia; AdministraDOR DE LA EDUCACIÓN.

\section{INTRODUÇÃo}

Este estudo, parte de uma dissertação de mestrado, analisa a percepção de diretoras sobre os desafios e as dificuldades da prática de Educação Física na pré-escola, para o atendimento às crianças, em três municípios da região do Grande $\mathrm{ABC}$. Trata-se de uma área que apresenta altos indicadores sociais e educacionais, localizada na região metropolitana de São Paulo. 
A Educação Infantil e a Educação Física possuem extrema relevância dentro do contexto da educação brasileira. Ambas são reconhecidas por suas particularidades e suas contribuições para a formação e para o desenvolvimento das crianças e dos jovens.

A Educação Infantil avançou muito no Brasil com a publicação da Constituição Federal de 1988 (CF/1988), onde a criança, entre outras questões, foi reconhecida como um sujeito de direito. Avançou também com a promulgação da Lei nº .8 .069 , de 13 de julho de 1990, o Estatuto da Criança e do Adolescente (BRASIL, 1990), que assegurou os direitos fundamentais da pessoa humana para que essa possa ter um "[...] desenvolvimento físico, mental, moral, espiritual e social, em condições de liberdade e dignidade" (BRASIL, 1990); e com a Lei de Diretrizes e Bases da Educação Nacional, Lei nº 9.394/96, que inseriu a Educação Infantil como primeira etapa da educação básica.

Os artigos 29 e 30 da LDBEN/96 enfatizaram o desenvolvimento integral da criança nos aspectos físico, psicológico, intelectual e social, preconizando que a criança é um ser integral e singular, que merece ser tratada de forma individual a partir do cuidar e do educar. Os artigos 11, 12 e 13, dessa legislação, indicaram que os municípios são os responsáveis por oferecer a Educação Infantil em creches e pré-escolas, administrando a proposta pedagógica, o pessoal e os recursos financeiros.

Além da CF/88, do Estatuto da Criança e do Adolescente e da LDBEN/96, outros documentos buscaram melhorar a qualidade da Educação Infantil no Brasil. Entre 1994 a 1996, o Ministério de Educação lançou um conjunto de documentos para uma Política Nacional de Educação Infantil (BRASIL, 1994). Orientações e diretrizes pedagógicas foram instituídas com o intuito de ampliar a oferta de vagas e promover a melhoria da qualidade de atendimento desse segmento. Em 1995, foi publicada a primeira edição dos Critérios de Atendimento nas Creches (BRASIL, 2009). Em 1998 foram lançados os documentos Subsídios para Credenciamento e o Funcionamento das Instituições de Educação Infantil (BRASIL, 1998) e o Referencial Curricular Nacional para a Educação infantil - RCNEI - (BRASIL, 1998), um documento que contribuiu com a construção e a implementação de práticas e de atividades educativas nas escolas e, ao mesmo tempo, com a qualidade da educação nesse nível.

Ainda na década de 1990, o Conselho Nacional de Educação (CNE) lançou as Diretrizes Nacionais Curriculares para a Educação infantil (BRASIL, 1998). Tal documento tinha o objetivo de orientar os encaminhamentos didáticos e pedagógicos para a Educação Infantil nos sistemas municipais e estaduais de educação e contribuir com a qualidade nesse nível de ensino. Em 2001, foi promulgada a Lei ${ }^{\circ}$. 10.172/2001 (Plano Nacional de Educação), de 9 de janeiro de 2001, criando metas para todos os níveis a fim de melhorar a educação brasileira. Esse plano durou até o ano de 2010. Em 2009, foi aprovada a Emenda Constitucional $\mathrm{n}^{\circ}$. 59/2009, de 11 de novembro de 2009, que, entre muitas coisas, ampliou a obrigatoriedade do ensino dos 4 aos 17 anos de idade. Tal legislação indicou que a pré-escola, que atende a alunos de 4 e 5 anos de idade, seria, a partir dessa emenda, parte do ensino compulsório no Brasil. Em 2014, foi publicado o Plano Nacional de Educação, lei 13.005 , de 25 de junho, que trouxe na primeira meta a questão de universalizar a Educação Infantil na pré-escola para as crianças de 4 a 5 anos de idade, ao mesmo tempo, ampliar a oferta de creches. 
Todavia, salienta-se que apesar de todo o avanço da legislação nos últimos anos, Barreto (1998) indicou que há vários desafios existentes para efetivar o direito das crianças à educação no que tange ao acesso ao ensino e à qualidade no atendimento.

No caso da Educação Física, a primeira LDBEN/61, Lei nº. 4.024, de 20 de dezembro de 1961, sinalizou, pela primeira vez, sua obrigatoriedade. Na década de 1970, a Lei $\mathrm{n}^{\circ}$. 5.692, de 11 de agosto de 1971, indicou sua obrigatória nos currículos, e o Decreto $\mathrm{n}^{\circ}$. 69.450 , de $1^{\circ}$. de novembro de 1971, a regulamentou nos três níveis de ensino. Nos anos de 1990, a LDBEN/96 estabeleceu sua inserção integral na proposta pedagógica da escola, instituindo-a como componente curricular obrigatório na Educação Infantil. Uma situação que seria confirmada pela Lei Federal $\mathrm{n}^{\mathrm{o}} .10 .793$, de $1^{\circ}$. de dezembro de 2003.

Em 1997, os Parâmetros Curriculares Nacionais (PCN, 1997) indicaram que a Educação Física tinha objetivos mais amplos e educacionais do que sua ligação com o esporte e com a melhoria da aptidão física. Nesse caso, outras dimensões, social, cultural e política, passaram a integrar suas bases filosóficas.

Os Parâmetros Curriculares Nacionais, 1997, sinalizaram que os conhecimentos de Educação Física estão atrelados à perspectiva da cultura corporal de movimento, que considera as experiências e as manifestações advindas dos alunos. Esse documento, de fato, ampliou as perspectivas da Educação Física, destacando sua importância para a formação das crianças, em especial para o desenvolvimento dos aspectos físicos, motores, cognitivos, sociais e afetivos.

Nesse contexto, a Educação Física assume destaque por sua importância na formação da criança e do jovem e, nesse sentido, ela "favorece o desenvolvimento físico, psíquico e social da criança, isto é o seu desenvolvimento integral" (CERÓSIMO; SATO, 2003, p. 125).

De acordo com Graber e Woods (2014), a Educação Física atua na transmissão de conhecimentos para as crianças e jovens em três domínios: psicomotor, cognitivo e afetivo. Outros pesquisadores indicaram que ela é "uma das disciplinas, integradas à proposta pedagógica da escola, que pode ajudar no ensino de estratégias de aprendizagem desde a educação infantil" (ÁVILA; FRISON, 2012, p. 182).

Para Alves (2011), a Educação Física atua para além das questões físicas, do intelecto e das relações sociais. Ela não se circunscreve somente aos conteúdos associados à esportivização. De fato, ela tem ligações sólidas com a formação integral do cidadão.

Magalhães, Kobal e Godoy (2007) sinalizaram que a aula de Educação Física é o espaço propício para um aprendizado, nos aspectos cognitivos, social, motor e emocional, por meio das brincadeiras e, nesse sentido, Rolim (2004) sinalizou que ela auxilia na alfabetização e Gonzáles e Fraga (2012) indicaram que ela está atrelada à interdisciplinaridade.

Para Kunz (2001), em relação à prática pedagógica da Educação Física na Educação Infantil, o desenvolvimento de movimentos proporciona para a criança um conhecimento maior sobre si mesma e, também, sobre o espaço e sobre o mundo em que ela está envolvida.

Como indicaram Gallahue e Ozmun (2005), a Educação Física na Educação Infantil é necessária porque atua no desenvolvimento integral da criança e, nesse sentido, Freire (1997) apontou que ela auxilia no raciocínio lógico-matemático. Esses autores reforçam a compreensão da relevância desse componente curricular na formação das crianças.

De acordo com Basei (2008), a Educação Física infantil: 
[...] tem um papel fundamental na educação infantil, pela possibilidade de proporcionar às crianças uma diversidade de experiências através de situações nas quais elas possam criar, inventar, descobrir movimentos novos, reelaborar conceitos e ideias sobre o movimento e suas ações. Além disso, é um espaço para que, através de situações de experiências - com o corpo, com materiais e de interação social - as crianças descubram os próprios limites, enfrentem desafios, conheçam e valorizem o próprio corpo, relacionem-se com outras pessoas, percebam a origem do movimento, expressem sentimentos, utilizando a linguagem corporal, localizem-se no espaço, entre outras situações voltadas ao desenvolvimento de suas capacidades intelectuais e afetivas, numa atuação consciente e crítica (BASEI, 2008, p. 1).

A Educação Física, de fato, tem enorme potencial para contribuir com o desenvolvimento da criança na Educação Infantil. Nesse sentido, atividades, experiências, desafios, jogos simbólicos e outras atividades, como aquelas relacionadas à imaginação, entre outras, contribuem nesse processo de formação, sobretudo, porque, atualmente, muitas crianças vivem em apartamentos e sem condições nem espaços para o brincar.

Ayoub (2001) afirma que a Educação Física na Educação Infantil, além de outras questões, cria espaços onde a criança pode brincar com a linguagem corporal, utilizando, para tal, o movimento. Dessa forma, ela entra em contato com as diferentes manifestações da cultura corporal, entre outras.

Vieira (2007) sinaliza que para a efetivação, de fato, da Educação Física na Educação Infantil, é necessário que seu projeto educativo supere a fragmentação e atue na singularidade e nas potencialidades das crianças em um espaço escolar lúdico. Nesse sentido, ela atua, entre outras coisas, contribuindo para a ampliação da leitura de mundo das crianças em uma perspectiva histórico-cultural.

Segundo Gallahue e Donnelly (2008), enfatizando a importância da Educação Física, é durante o período da Educação Infantil que se desenvolvem funções cognitivas que resultam em pensamentos lógicos e na formulação de conceitos. Trata-se, de acordo com Vokoy e Pedroza (2005), de um período em que a criança está mais propensa à formação de atitudes que podem marcar de forma prolongada seu comportamento em relação ao meio.

É nessa fase da Educação Infantil que as crianças possuem necessidades naturais de realizar movimentos, de brincar e de aprender e, nesse sentido, é fundamental motivá-las para a exploração e para a descoberta por meio de brincadeiras de atividades lúdicas.

Gallardo (2003, p. 33) sinalizou que as atividades lúdicas encantam as crianças, pois o "brincar é o estímulo que a criança recebe, colocando espontaneamente em ação os seus movimentos, e explorando intensamente seu potencial motriz, realizando assim novas descobertas de movimentos que consegue executar".

Entre as múltiplas discussões sobre a Educação Física, tanto como componente curricular quanto área de conhecimento na Educação Infantil, está aquela relacionada à formação inicial do professor. Um debate que tem indicado, entre outras questões, a precariedade da formação, a ausência de conhecimentos em educação, a falta de competências para a gestão das aulas, além de inadequação do estágio profissional, entre outras coisas (SILVA, 2011; PAIXÃO; BARROSO; CUSTÓDIO, 2016; PIMENTA, 2011; AYOUB, 2005; LEITE, 2008; NEIRA, 2012; LEONE; LEITE, 2011; D’AVILA, 2016, entre outros). 
Há também grande discussão sobre a questão das aulas de Educação Física que, em muitos contextos, são ministradas pela própria professora de sala de aula, uma profissional com formação em pedagogia e, algumas vezes, no antigo magistério.

De fato, Bohme (1985) já havia sinalizado que a maioria das aulas de Educação Física nas redes de ensino estadual e municipal era ministrada pela professora generalista, a própria regente da sala de aula. Em contrapartida, na rede particular, elas eram ministradas pelo professor especialista.

As pesquisas que analisaram a atuação desta profissional nas aulas de Educação Física na Educação Infantil sinalizaram que esta professora, formada no magistério, não apresenta formação, repertório suficiente, ou não está, adequadamente, preparada para lidar com as aulas de Educação Física no contexto da Educação Infantil.

A pesquisa de Arantes (1990), na busca por compreender o grau de capacitação profissional das professoras formadas no magistério, sinalizou que essas profissionais não atendiam às expectativas da aula de Educação Física na Educação Infantil, pois careciam de formação específica. As próprias professoras que participaram do estudo assumiram dificuldades em ministrar as aulas.

Ferraz (2000) apontou que quase a metade das professoras generalistas, por ele entrevistadas, não desenvolvia atividades físicas com as crianças por falta de conhecimentos para a prática pedagógica. De acordo com o autor, falta a essa profissional, formada nos cursos de magistério, sentido em suas práticas. As próprias profissionais indicaram preferências por um especialista em Educação Física para ministrar as aulas.

Mello (2007) indicou que na Educação Infantil existem poucos exemplos, em poucas cidades, onde as aulas de Educação Física são ministradas por professores formados na área. O mesmo autor sinalizou também que, muitas vezes, essas professoras generalistas não possuem conhecimentos para atuar com as crianças de 0 a 6 anos de idade. Nesse sentido, as aulas de Educação Física não possuem qualquer tipo de sistematização e estão muito vinculadas às atividades esportivas.

Estudos realizados pelo Observatório da Educação da região do Grande $\mathrm{ABC}$, em 2016, em duas universidades da região, revelaram que as futuras professoras, formadas nos cursos de pedagogia, apresentavam dificuldades em ministrar as aulas de Educação Física para as crianças de pré-escola. Tal fato, de acordo com o estudo, era proveniente da ausência de conhecimentos e de competências sobre a Educação Física nessa faixa etária, da pouca vivência ministrando esse tipo de aula, da falta de confiança e da preferência pelo profissional especializado para realizar as aulas (OBEDUCABC, 2016).

Além desse desafio em relação à formação do professor que atua na Educação Infantil, há outro também a ser superado associado à infraestrutura escolar. De fato, a infraestrutura para as aulas de Educação Física é inadequada para atender às necessidades das crianças dessa faixa etária (GARCIA; GARRIDO; MARCONI, 2017), apesar de ela ser determinante para a organização de ambientes de aprendizagem para o desenvolvimento da criança.

Este mesmo estudo revelou que as escolas apresentavam infraestrutura (instalações, equipamentos, materiais, entre outros) inadequada e diversificada, com grande variabilidade entre elas. Aquilo que mais preocupou os pesquisadores foi a questão de que essa variação estava presente dentro de uma mesma cidade, situação que sinaliza que crianças 
em um mesmo município tinham oportunidades de aprendizagem diferentes nas aulas de Educação Física.

Ainda no contexto da Educação Física na Educação Infantil, cabe ressaltar a importância do diretor da escola. Trata-se de um profissional que deve exercer liderança, orientar e mobilizar as pessoas, profissionais da educação, em função dos objetivos para melhorar a qualidade da Educação Física na Educação Infantil.

Para Garcia (2010), o diretor tem um papel fundamental nas inovações e mudanças, pois organiza e mobiliza as pessoas, os contextos (administrativo e pedagógico), os recursos, as aprendizagens educacionais, entre outros.

Estudo organizado pelo Observatório de Educação do Grande ABC (OBEGABC, 2015) mostrou que todos os diretores da Educação Infantil da região eram mulheres, casadas, com, em média, 51 anos de idade. Elas eram formadas em pedagogia (90\%), em faculdades privadas e cursos presenciais. Essas profissionais possuíam algum tipo de pós-graduação, experiência na gestão escolar e tinham uma carga horária média de trabalho de 40 horas semanais.

Sintetizando, destacou-se a importância da Educação Física na Educação Infantil para a formação e o desenvolvimento da criança, a partir do lúdico e da brincadeira, entre outras questões. Ressaltou também alguns problemas em relação à professora que tem ministrado as aulas, em geral a regente da sala, e a inadequação da infraestrutura para as aulas. Paralelamente, revelou-se a relevância da diretora na organização escolar e curricular para as aulas de Educação Física. É nesse contexto que se insere este estudo, o qual realiza uma análise da percepção de diretoras sobre os desafios e as dificuldades da prática de Educação Física na pré-escola, para o atendimento às crianças. Sua realização ocorreu em três municípios da região do Grande ABC.

\section{Metodologia}

Este estudo, parte de uma dissertação de mestrado, analisa a percepção de diretoras sobre os desafios e as dificuldades da prática de Educação Física na pré-escola, para o atendimento às crianças, em três municípios da região do Grande $\mathrm{ABC}$.

A região do Grande $\mathrm{ABC}$ foi selecionada, considerando que se versa sobre uma localidade brasileira com altos níveis socioeconômico e educacional. Trata-se de uma área que apresenta uma realidade diferente e difícil de ser encontrada em outras regiões do país e, nesse sentido, adequada para este estudo.

Este estudo utilizou a metodologia qualitativa, descritiva e exploratória, que se apresenta como uma abordagem aberta e flexível, sendo propícia para a investigação do problema no contexto analisado. Esta abordagem atua no sentido de conhecer os significados envolvidos nos eventos e, ao mesmo tempo, de apreender a totalidade das relações sociais (FLICK, 2004). Procura-se, também, o desenvolvimento de elementos empíricos a partir da perspectiva das pessoas nos ambientes sociais onde elas estão inseridas. Neste tipo de pesquisa são usados diversos procedimentos, alguns racionais, outros mais intuitivos, a fim de compreender melhor o fenômeno estudado (NEVES, 1996).

Neste estudo, duas fases, apesar de distintas, se complementaram ao redor do fenômeno estudado. Na primeira, os procedimentos metodológicos se associaram à pesquisa do- 
cumental, que, para Gil (2002), usa, essencialmente, os "materiais que não recebem ainda um tratamento analítico, ou que ainda podem ser reelaborados de acordo com os objetos de pesquisa" (p. 45).

Nessa fase, nos sítios das Secretarias de Educação, foram coletados os seguintes documentos: a) Na cidade de São Bernardo do Campo, a Proposta Curricular Educação Infantil, volume 2, Caderno 2, de 2007; b) na cidade de São Caetano do Sul, as Orientações Curriculares para a Educação Infantil (2013); c) na cidade de Santo André não havia um documento publicado sobre as orientações curriculares. De acordo com a Secretaria de Educação, as escolas utilizavam como referência o Referencial Curricular Nacional para a Educação Infantil (BRASIL, 1998). Essas referências estavam incluídas nos Projetos Políticos Pedagógicos (PPPs) da cidade. Todavia, pela multiplicidade de PPPs, cada escola possuía um diferente, optou-se por não realizar qualquer tipo de análise.

$\mathrm{Na}$ segunda fase foram entrevistadas, a partir de entrevistas semiestruturadas, diretoras de pré-escolas para analisar, nos três municípios do Grande ABC, a percepção delas sobre os desafios e as dificuldades da prática de Educação Física na pré-escola.

Triviños (1987) situa que a entrevista semiestruturada é adequada para realização de questionamentos básicos, apoiados em teorias e hipóteses relacionadas ao tema de pesquisa. Para esse autor, ela "favorece não só a descrição dos fenômenos sociais, mas também sua explicação e a compreensão de sua totalidade, além de manter a presença consciente e atuante do pesquisador no processo de coleta de informações" (TRIVIÑOS, 1987, p. 152).

Nesse contexto, foram entrevistadas 45 diretoras, conforme a síntese na Tabela 1:

Tabela 1: Número de participantes do estudo.

\begin{tabular}{lcc} 
Município & Diretoras entrevistadas & Pré-escolas \\
\hline Santo André & 12 & 46 \\
São Bernardo & 15 & 68 \\
\hline São Caetano & 18 & 24 \\
\hline Total & $\mathbf{4 5}$ & $\mathbf{1 3 8}$ \\
\hline
\end{tabular}

Fonte: dados das entrevistas. Elaboração do autor (2018).

Com essas diretoras foi traçado o perfil em termos de sexo, idade, moradia, estado civil, formação, tipo de instituição e tipo de curso realizado, experiência no magistério, tempo de trabalho e carga horária semanal. Ao mesmo tempo, foram coletadas informações acerca dos desafios e as dificuldades quanto à Educação Física na pré-escola. Nesse caso, foram reunidos dados sobre as categorias previamente estabelecidas: a) o profissional que ministra as aulas, b) os locais das aulas, c) a relevância da Educação Física na pré-escola, d) os desafios e as dificuldades enfrentadas no cotidiano escolar.

Os dados da primeira e da segunda fase foram analisados, a partir da análise de conteúdo. Nesse contexto, foram utilizadas como referencial de análise as indicações e as diretrizes de autores como Bardin (1977) e Franco (2012), que realizaram orientações preciosas sobre esse tipo de trabalho. Dessa forma, foi realizada uma pré-análise das informações, como sugerem os autores, a partir da apreciação da mensagem, que traz significado e sentido. Bardin (1977) sugere que a mensagem seja decodificada com o intuito de compreender seu significado e, com isso, contribuir para a compreensão do problema proposto. 
Neste presente estudo, a análise dos dados, realizada a partir das entrevistas com as diretoras de pré-escolas, contou com categorias previamente criadas pelo pesquisador que são apresentadas nos resultados. Portanto, elas foram criadas aprioristicamente. Todavia, na análise de documentos, as categorias surgiram à medida que as informações eram analisadas. Dessa forma, criadas não aprioristicamente.

\section{ReSUlTAdOS E DISCUSSÕES}

São apresentados, inicialmente, os dados do perfil dos participantes deste estudo. A seguir, são reveladas as análises das informações advindas dos documentos encontrados nas três cidades, e por fim as entrevistas com as diretoras ${ }^{1}$ de escola.

\section{O PERFIL DAS DIRETORAS}

Os dados do perfil são apresentados na Tabela 2. Eles são revelados a partir de um conjunto de categorias associadas ao sexo, idade, formação das participantes, experiência e carga horária de trabalho:

Tabela 2: Perfil das participantes.

\begin{tabular}{|c|c|c|c|}
\hline Cidade & Santo André & $\begin{array}{c}\text { São } \\
\text { Bernardo }\end{array}$ & $\begin{array}{c}\text { São } \\
\text { Caetano }\end{array}$ \\
\hline Sexo & $\begin{array}{c}\text { Feminino } \\
(100 \%)\end{array}$ & $\begin{array}{l}\text { Feminino } \\
(100 \%)\end{array}$ & $\begin{array}{c}\text { Feminino } \\
(100 \%)\end{array}$ \\
\hline Idade média & 47 anos & 45 anos & 52 anos \\
\hline Estado civil & $\begin{array}{l}\text { Casadas } \\
(50 \%)\end{array}$ & $\begin{array}{l}\text { Casadas } \\
(90 \%)\end{array}$ & $\begin{array}{l}\text { Casadas } \\
(100 \%)\end{array}$ \\
\hline Formação & $\begin{array}{l}\text { Pedagogia } \\
(100 \%)\end{array}$ & $\begin{array}{c}\text { Pedagogia } \\
(90 \%)\end{array}$ & $\begin{array}{c}\text { Pedagogia } \\
(100 \%)\end{array}$ \\
\hline Tipo de faculdade & $\begin{array}{l}\text { Privada } \\
(75 \%)\end{array}$ & $\begin{array}{l}\text { Privada } \\
(100 \%)\end{array}$ & $\begin{array}{l}\text { Privada } \\
(100 \%)\end{array}$ \\
\hline Tipo de curso & $\begin{array}{c}\text { Presencial } \\
(85 \%)\end{array}$ & $\begin{array}{c}\text { Presencial } \\
(100 \%)\end{array}$ & $\begin{array}{c}\text { Presencial } \\
(100 \%)\end{array}$ \\
\hline Pós-graduação & $\begin{array}{l}\operatorname{Sim} \\
(75 \%)\end{array}$ & $\underset{(100 \%)}{\operatorname{Sim}}$ & $\underset{(100 \%)}{\operatorname{Sim}}$ \\
\hline $\begin{array}{l}\text { Experiência média em } \\
\text { educação }\end{array}$ & 27 anos & 25 anos & 27 anos \\
\hline $\begin{array}{l}\text { Experiência em direção } \\
\text { de escola }\end{array}$ & 20 anos & 16 anos & 20 anos \\
\hline Carga horária & 40 horas & 40 horas & 40 horas \\
\hline
\end{tabular}

Fonte: Elaboração do autor (2018).

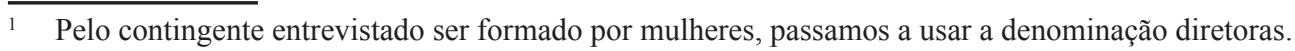


Em relação ao perfil das diretoras das pré-escolas dos três municípios, algumas características são muito similares. O grupo é caracterizado por mulheres, a grande maioria era formada em Pedagogia, em faculdades privadas, em cursos presenciais e com algum tipo de pós-graduação em alguma área relacionada à educação. Eram profissionais experientes, com mais de 25 anos de experiência em educação e mais de 20 anos na direção de escola. Todas atuavam 40 horas semanais.

A questão a se destacar relaciona-se ao fato de que muitas dessas profissionais estarão aposentadas nos próximos anos e muitas das experiências profissionais se perderão. Tal fato pode ser considerado um alerta para as autoridades políticas e educacionais das três cidades e, como indicaram Garcia et al., (2016), as secretarias de educação dos municípios poderiam criar algum tipo de programa para captar um pouco do conhecimento e da experiência acumuladas por essas diretoras que ainda não se aposentaram. Poderiam ser construídos materiais, como videoaulas, trazendo um pouco de seus conhecimentos, assim como algumas recomendações. Tal situação seria uma estratégia para o desenvolvimento de recursos humanos especializados. Dessa forma, os novos profissionais que ingressassem na rede poderiam aproveitar algumas das experiências daquelas que atuaram nas escolas durante anos.

\section{OS DADOS DOS DOCUMENTOS}

Nesta parte do artigo são apresentados os dados da análise de documentos. O Quadro 1 exibe uma síntese a partir dos dois municípios analisados, mostrando as categorias analisadas:

\section{Quadro 1: Síntese dos dados encontrados nos documentos.}

\begin{tabular}{|l|l|l|l|}
\hline Categoria/cidades & Santo André & São Bernardo & São Caetano \\
\hline $\begin{array}{l}\text { Documento } \\
\text { orientador }\end{array}$ & $\begin{array}{l}\text { Sem um } \\
\text { documento } \\
\text { orientador. } \\
\text { Orientações } \\
\text { definidas pelos } \\
\text { Referenciais } \\
\text { Curriculares do } \\
\text { MEC. }\end{array}$ & $\begin{array}{l}\text { Proposta Curricular } \\
\text { Educação Infantil: } \\
\text { (2007). }\end{array}$ & $\begin{array}{l}\text { Orientações Curriculares } \\
\text { para a Educação Infantil / } \\
\text { Secretaria de Educação }\end{array}$ \\
\hline Eixo & & Corpo e movimento. & Movimento \\
\hline $\begin{array}{l}\text { Premissas de } \\
\text { fundamentação }\end{array}$ & & $\begin{array}{l}\text { Ancoradas em Piaget, } \\
\text { (1998). }\end{array}$ & $\begin{array}{l}\text { Base norteadora do } \\
\text { documento é o Referencial } \\
\text { Curricular Nacional da } \\
\text { Educação Infantil (RCNEI, } \\
\text { 2010) e autores consagrados } \\
\text { como Piaget, Wallon, } \\
\text { Vigotsky, entre outros. }\end{array}$ \\
\hline
\end{tabular}




\begin{tabular}{|c|c|c|c|}
\hline Categoria/cidades & Santo André & São Bernardo & São Caetano \\
\hline Organização & - & $\begin{array}{l}\text { Presença de } \\
\text { objetivos, conteúdos, } \\
\text { habilidades, formas } \\
\text { de organização, } \\
\text { orientações para os } \\
\text { professores. }\end{array}$ & $\begin{array}{l}\text { Presença de objetivos, } \\
\text { conteúdos, habilidades, } \\
\text { formas de organização, } \\
\text { orientações para os } \\
\text { professores. }\end{array}$ \\
\hline $\begin{array}{l}\text { Fundamentos } \\
\text { educacionais }\end{array}$ & & $\begin{array}{l}\text { Fundamentado no } \\
\text { brincar a partir da } \\
\text { utilização de jogos, } \\
\text { brincadeiras, danças, } \\
\text { música. }\end{array}$ & $\begin{array}{l}\text { Ancorados no acolhimento, } \\
\text { no cuidar e educar, e no } \\
\text { brincar, a partir da utilização } \\
\text { de jogos, brincadeiras, dança } \\
\text { e música. }\end{array}$ \\
\hline Objetivos & & $\begin{array}{l}\text { Em geral, os objetivos } \\
\text { estão atrelados a } \\
\text { induzirem as crianças } \\
\text { a se perceber, a } \\
\text { explorar e participar } \\
\text { por meio do brincar. }\end{array}$ & $\begin{array}{l}\text { Em geral, os objetivos estão } \\
\text { atrelados a induzirem as } \\
\text { crianças a se perceber, a } \\
\text { explorar, a participar por } \\
\text { meio do brincar. Ênfase } \\
\text { grande na formação de } \\
\text { atitudes. }\end{array}$ \\
\hline Conteúdos & & $\begin{array}{l}\text { Conteúdos } \\
\text { estruturados em dois } \\
\text { blocos: possibilidades } \\
\text { expressivas do } \\
\text { movimento/função } \\
\text { tônica, e caráter } \\
\text { instrumental/ função } \\
\text { cinética. }\end{array}$ & $\begin{array}{l}\text { Conteúdos integrados } \\
\text { com os objetivos e, } \\
\text { em geral, buscam a } \\
\text { exploração, a ampliação de } \\
\text { capacidades, a participação } \\
\text { e a experimentação, entre } \\
\text { outras questões para o } \\
\text { desenvolvimento das } \\
\text { crianças. }\end{array}$ \\
\hline $\begin{array}{l}\text { Organização do } \\
\text { trabalho }\end{array}$ & & $\begin{array}{l}\text { Distribuído em: } \\
\text { espaço e materiais, } \\
\text { relações pessoais e as } \\
\text { dimensões do tempo. }\end{array}$ & $\begin{array}{l}\text { A partir da expressividade } \\
\text { (cultura lúdica, brincar } \\
\text { espontâneo e movimentos } \\
\text { expressivos) e do equilíbrio } \\
\text { e coordenação (apropriação } \\
\text { e consciência corporal). }\end{array}$ \\
\hline Estratégias de ensino & & $\begin{array}{l}\text { As estratégias } \\
\text { de ensino e } \\
\text { aprendizagem são } \\
\text { baseadas em quatro } \\
\text { tipos de atividades: } \\
\text { jogos e brincadeiras, } \\
\text { exploração de } \\
\text { materiais, circuitos } \\
\text { e ritmos, e danças e } \\
\text { rodas cantadas. }\end{array}$ & $\begin{array}{l}\text { As estratégias de ensino e } \\
\text { aprendizagem são baseadas } \\
\text { em brincadeiras, exploração } \\
\text { de materiais, jogos, circuitos, } \\
\text { danças e rodas cantadas. }\end{array}$ \\
\hline
\end{tabular}




\begin{tabular}{|c|c|c|c|}
\hline Categoria/cidades & Santo André & São Bernardo & São Caetano \\
\hline $\begin{array}{l}\text { Orientações para os } \\
\text { professores }\end{array}$ & & $\begin{array}{l}\text { Presença de } \\
\text { orientações para os } \\
\text { professores, entre } \\
\text { elas: organizar } \\
\text { ambientes de } \\
\text { aprendizagem e } \\
\text { propor atividades } \\
\text { nas quais as } \\
\text { crianças tenham } \\
\text { maior autonomia, } \\
\text { acompanhar o } \\
\text { desenvolvimento das } \\
\text { crianças, intervirem } \\
\text { nas atividades, } \\
\text { considerar a } \\
\text { ludicidade presente } \\
\text { nessa proposta, } \\
\text { respeitar o interesse } \\
\text { das crianças, permitir } \\
\text { que elas definam } \\
\text { as ações sobre os } \\
\text { materiais, entre } \\
\text { outras. }\end{array}$ & $\begin{array}{l}\text { Presença de orientações para } \\
\text { os professores: observar } \\
\text { as crianças, acolher, fazer } \\
\text { perguntas, organizar } \\
\text { ambientes de aprendizagem, } \\
\text { propor atividades, avaliar } \\
\text { o desenvolvimento das } \\
\text { crianças, intervir nas } \\
\text { atividades, respeitar o } \\
\text { interesse das crianças, entre } \\
\text { outras. }\end{array}$ \\
\hline $\begin{array}{l}\text { Competências que os } \\
\text { professores devem } \\
\text { ter }\end{array}$ & & & $\begin{array}{l}\text { Estão presentes nas } \\
\text { Orientações Curriculares } \\
\text { relacionadas ao domínio } \\
\text { dos conteúdos curriculares } \\
\text { e das características do } \\
\text { desenvolvimento das } \\
\text { crianças, a realização do } \\
\text { planejamento e organização } \\
\text { de ambientes atrativos e } \\
\text { prazerosos para as crianças. }\end{array}$ \\
\hline
\end{tabular}

Fonte: Propostas curriculares - Elaboração dos autores (2018).

A análise dos documentos possibilitou a criação de 11 categorias: documento orientador, eixos, premissas de fundamentação, organização, fundamentos educacionais, objetivos, conteúdos, estratégias de ensino, orientações e competências dos professores. De fato, uma análise realizada pelo Observatório da região do Grande ABC, em 2015, havia revelado que os currículos de Educação Física na Educação Infantil, de dois municípios, apresentavam conteúdo e forma muito similar (OBEDUCGABC, 2015). Tais documentos foram construídos por profissionais que atuavam nas próprias Secretarias de Educação.

As cidades de São Bernardo e de São Caetano possuíam as diretrizes curriculares para suas redes de ensino. No primeiro município havia uma proposta curricular assentada no eixo corpo e movimento e, no segundo, as orientações eram ancoradas no movimento.

Os dois documentos apresentaram bases filosóficas e epistemológicas ancoradas nas ideias de pesquisadores consagrados como Piaget, Wallon e Vigotsky e, também, assentadas no Referencial Curricular Nacional da Educação Infantil. Todavia, salienta-se que as 
indicações nos textos careciam de detalhamento e aprofundamento teórico (OBEDUCGA$\mathrm{BC}, 2015)$.

Os documentos traziam uma organização muito similar ancorada em objetivos, conteúdos, formas de organização, orientações para os professores, entre outros. Entre as poucas diferenças encontradas, estava a questão de que na cidade de São Caetano os conteúdos e as habilidades tinham de ser desenvolvidos nas crianças.

Em relação aos fundamentos educacionais, ambos os documentos indicavam o brincar, por meio de jogos e brincadeiras, como elemento-chave no processo de aprendizagem da criança. Essa é uma indicação relevante, pois, como indicou Ayoub (2001), a Educação Física na Educação Infantil necessita do brincar para desenvolver, entre muitas coisas, o movimento e para a criança interagir com manifestações da cultura corporal. Em São Caetano apareceram, também, questões relacionadas ao acolhimento, ao cuidar e ao educar.

As duas propostas traziam de forma clara a presença de objetivos e de conteúdos. No primeiro caso, objetivos, esses se relacionavam, em geral, à questão das crianças se perceberem, atuarem na exploração dos ambientes e dos espaços e na participação por meio do brincar. No segundo, em São Bernardo, o documento indicava que eles (conteúdos) estavam estruturados em dois blocos: possibilidades expressivas do movimento/função tônica e caráter instrumental/função cinética. Em São Caetano, eles estavam integrados aos objetivos e se desenrolavam sobre a exploração, a ampliação de capacidades, a participação e a experimentação.

Na questão da organização do trabalho, São Bernardo tinha uma distribuição relacionada aos espaços e materiais, às relações pessoais e às dimensões do tempo. Em São Caetano, ela acontecia a partir da expressividade (cultura lúdica, brincar espontâneo e movimentos expressivos) e do equilíbrio e coordenação (apropriação e consciência corporal).

Ambas as cidades dispunham, em seus documentos, de estratégias de ensino que, em geral, eram bem similares e baseadas em jogos, brincadeiras, na exploração de materiais, nas danças, na música, entre outros.

Essas propostas dispunham também de orientações para os professores que também eram bem similares e se relacionavam, entre outras coisas, à questão de organizar espaços, propor atividades, observar as crianças e intervir para seu desenvolvimento. Todavia, tais indicações eram, muitas vezes, superficiais e careciam de detalhamento. Particularidade similar àquela encontrada em estudo anterior (OBEDUCGABC, 2015).

No documento de São Caetano havia um item sobre competências que os professores necessitavam ter para atuar com as crianças. Essas estavam relacionadas à questão do domínio dos conteúdos curriculares e das características do desenvolvimento das crianças, do planejamento e da organização de ambientes atrativos e prazerosos, entre outros. Essa indicação é muito relevante, considerando que as futuras professoras carecem de conhecimentos e de competências acerca da Educação Física, dispõem de pouca vivência sobre as aulas e lhes falta confiança para esse tipo de atuação (OBEDUCABC, 2016).

Essa análise das particularidades encontradas nos documentos das duas cidades mostrou muito mais similaridades do que diferenças entre as propostas curriculares. A apreciação revelou também similaridades com documentos mais recentes, como o texto sobre a Educação Física na Educação Infantil da rede municipal de ensino de Florianópolis, de 2016 (SMEFL, 2016).

Foi possível verificar nos documentos analisados preocupações das autoridades educacionais em relação à Educação Física na pré-escola, a partir de sinalização de objetivos, conteúdos, indicações para o trabalho do professor e premissas fundamentais associadas 
à formação e ao desenvolvimento das crianças. Os documentos apresentaram características de caráter mais instrumental, mas assentado em teorias sólidas do campo do currículo da Educação Infantil.

\section{Os dados das entrevistas}

O Quadro 2 apresenta uma síntese dos dados coletados e analisados nas entrevistas realizadas com as diretoras das escolas. São elementos empíricos trazidos por 45 profissionais que atuavam em pré-escolas.

Quadro 2: Apontamentos e percepções das diretoras.

\begin{tabular}{|c|c|c|c|}
\hline & Santo André & São Bernardo & São Caetano \\
\hline $\begin{array}{l}\text { Profissional } \\
\text { que ministra } \\
\text { as aulas }\end{array}$ & $\begin{array}{l}\text { - Há o profissional especialista em } \\
\text { Educação Física quando se trata de } \\
\text { uma Escola Municipal de Educação } \\
\text { Infantil e Ensino Fundamental } \\
\text { (EMEIF), mas não em uma creche que } \\
\text { também atende crianças de pré-escola } \\
\text { (professora polivalente). } \\
\text { - Os professores têm autonomia } \\
\text { quanto aos aspectos didáticos } \\
\text { metodológicos. } \\
\text { - Aulas organizadas duas vezes por } \\
\text { semana com, em média, } 60 \text { minutos. }\end{array}$ & $\begin{array}{l}\text { - Não há especialista } \\
\text { para ministrar as aulas. } \\
\text { Professora generalista. } \\
\text { - Professoras têm } \\
\text { autonomia quanto aos } \\
\text { aspectos didáticos } \\
\text { metodológicos. } \\
\text { - Aulas organizadas duas } \\
\text { vezes por semana com, em } \\
\text { média, } 60 \text { minutos. } \\
\text { - A professora utiliza } \\
\text { como referências a } \\
\text { proposta curricular. }\end{array}$ & $\begin{array}{l}\text { - Não há especialista } \\
\text { para ministrar as aulas. } \\
\text { Professora generalista. } \\
\text { - As professoras têm } \\
\text { autonomia quanto aos } \\
\text { aspectos didáticos e } \\
\text { metodológicos. } \\
\text { - Aulas organizadas } \\
\text { duas vezes por semana } \\
\text { com, em média, } 60 \\
\text { minutos. } \\
\text { - As professoras } \\
\text { precisam planejar as } \\
\text { aulas. }\end{array}$ \\
\hline $\begin{array}{l}\text { Local das } \\
\text { aulas }\end{array}$ & $\begin{array}{l}\text { Em geral, as aulas ocorrem nas } \\
\text { quadras ou nos pátios da escola. Às } \\
\text { vezes, elas acontecem em espaços } \\
\text { adaptados pelos professores. }\end{array}$ & $\begin{array}{l}\text { Em geral, locais como } \\
\text { pátios, parques infantis, } \\
\text { entre outros. }\end{array}$ & $\begin{array}{l}\text { Locais adaptados, } \\
\text { parques infantis, sala } \\
\text { de aula, jardim, quadra } \\
\text { esportiva. }\end{array}$ \\
\hline $\begin{array}{l}\text { Análise do } \\
\text { gestor sobre } \\
\text { a Educação } \\
\text { Física na } \\
\text { pré-escola }\end{array}$ & $\begin{array}{l}\text { - Educação Física na pré-escola é } \\
\text { fundamental para o desenvolvimento } \\
\text { das crianças. } \\
\text { - Atua na melhoria do movimento do } \\
\text { corpo como um todo e proporciona } \\
\text { desafios para que sejam transpostos. } \\
\text { - Professores especialistas realizam } \\
\text { semanalmente, em conjunto com seus } \\
\text { coordenadores ou diretoras, algum } \\
\text { tipo de formação e de planejamento. }\end{array}$ & $\begin{array}{l}\text { Educação Física na pré- } \\
\text { escola é fundamental para } \\
\text { o desenvolvimento das } \\
\text { crianças, }\end{array}$ & $\begin{array}{l}\text { - Educação Física } \\
\text { importante para a } \\
\text { formação das crianças. }\end{array}$ \\
\hline $\begin{array}{l}\text { Dificuldades } \\
\text { e desafios } \\
\text { enfrentados } \\
\text { pela gestão } \\
\text { escolar }\end{array}$ & $\begin{array}{l}\text { - Ausência (falta diária) de } \\
\text { professores de Educação Física nas } \\
\text { escolas. } \\
\text { - Falta de formação dos professores. } \\
\text { - Ausência de infraestrutura adequada. } \\
\text { - Furtos de materiais esportivos. }\end{array}$ & $\begin{array}{l}\text { - Ausência de uma } \\
\text { infraestrutura adequada. } \\
\text { - Falta de materiais em } \\
\text { muitas escolas. } \\
\text { - Falta de formação } \\
\text { adequada. }\end{array}$ & $\begin{array}{l}\text { - Falta do professor } \\
\text { especialista para } \\
\text { ministrar as aulas. } \\
\text { - Ausência de } \\
\text { uma infraestrutura } \\
\text { adequada. }\end{array}$ \\
\hline
\end{tabular}

Fonte: dados das entrevistas. Elaboração do autor (2018). 
Em primeiro lugar, destaca-se que, entre os municípios, apenas Santo André dispunha do professor especialista em Educação Física atuando na pré-escola. Mas, mesmo nesse contexto, vale ressaltar que esse profissional estava presente somente quando se tratava de uma Escola Municipal de Educação Infantil e Ensino Fundamental (EMEIEF).

Nas outras duas cidades, quem ministrava as aulas era a professora de sala de aula, a profissional generalista. Esses dados vão ao encontro das indicações de Mello (2007), quando o autor sinalizou que em poucas cidades brasileiras as aulas de Educação Física na pré-escola, sobretudo nas escolas públicas, eram ministradas por um professor especialista.

Nesse contexto, nas entrevistas, todas as diretoras sinalizaram a questão da ausência de formação adequada das professoras generalistas que ministravam as aulas para as crianças nas pré-escolas em relação, sobretudo, aos conhecimentos específicos da área de educação (filosofia, didática), entre outros. Uma diretora sinalizou que:

\footnotetext{
“...as professoras não apresentam boa formação e os cursos de formação de professores precisam ensinar didática e as fases das crianças, isto é, como elas aprendem na troca com os outros e o que eu como professora posso fazer para melhorar a vida da criança" (DIRETORA-14).
}

Outra profissional que participou do estudo indicou que "muitas professoras não foram bem formadas nessa área e precisam de cursos. Mas são poucos os que são oferecidos para elas" (DIRETORA-15). Outra diretora sinalou que a professora "não foi formada em conhecimentos da área, não sabe lidar com as questões do movimento, nem a questão do esporte" (DIRETORA-13).

Tal situação, em que as aulas são ministradas pela professora de sala de aula, pode indicar certa fragilidade na questão da Educação Física, em geral, e no processo de formação das crianças, em particular. De fato, como sinalizaram alguns autores (BOHME, 1985; ARANTES, 1990; FERRAZ, 2000; OBEGABC, 2016), essa profissional, muitas vezes, não apresenta preparação suficiente para a atuação com as crianças.

Nesse particular, essas profissionais, muitas vezes, não planejam as aulas nem realizam observações sobre as crianças, elementos fundamentais para o desenvolvimento integral das mesmas. Ao mesmo tempo, em muitos casos, essas profissionais não se sentem seguras para realizar as ações necessárias em relação à formação das crianças (OBEGABC, 2016), o que pode fazer que elas reduzam o tempo, entre outras coisas, das atividades de Educação Física e, nesse contexto, impossibilitem o desenvolvimento das crianças.

Em segundo lugar, destaca-se que as diretoras entrevistadas salientaram, de forma unânime, a importância da Educação Física na pré-escola para, entre muitas questões, atuar no desenvolvimento integral e na formação da criança. Uma profissional citou que "a Educação Física para essas crianças, com essa idade, nossa, é fundamental, pois elas usam o corpo para tudo e aprendem por meio do corpo" (DIRETORA-04). Outra diretora indicou que a "Educação Física é importante na alfabetização das crianças como nos ensinou Emília Ferrero" (DIRETORA-10). Por fim, outra profissional salientou que "por causa da importância da Educação Física na Educação Infantil é que o professor de Educação Física é fundamental" (DIRETORA-17). 
Essas profissionais destacaram elementos importantes da ação da Educação Física na pré-escola como a formação integral da criança, envolvendo os aspectos psicomotor, cognitivo, afetivo, social e sua capacidade de auxiliar no processo de alfabetização do aluno; o desenvolvimento de funções cognitivas que auxiliam no pensamento lógico e na formulação de conceitos, entre outros, sinalizações que vão ao encontro da literatura especializada da área (MAGALHÃES; KOBAL; GODOY, 2007; ROLIM, 2004; FERRAZ; MACEDO, 2001; KUNZ, 2001; GALLAHUE, OZMUN, 2005; BASEI, 2008; entre outros). No entanto, os dados deste estudo são relevantes, pois trazem as perspectivas daquelas que dirigem as escolas e que estão envolvidas no processo escolar, as diretoras, aquelas que, de acordo com Garcia (2010), são impulsionadores das inovações e mudanças educacionais e pedagógicas.

Em terceiro lugar, destaca-se que as diretoras indicaram a questão da infraestrutura escolar inadequada para a realização das aulas de Educação Física, pela ausência, entre outros locais, da quadra de esporte e da falta de materiais (colchões, cordas). Essas profissionais afirmaram que as aulas ocorrem em uma variedade de espaços, entre eles, o pátio, o parque infantil, as salas de aulas, em quadras poliesportivas ou em outros locais improvisados, como o jardim.

Uma profissional indicou que "a questão da falta de espaços é algo que temos de enfrentar e, com isso, em muitas atividades os professores têm de improvisar. Isso é geral, você vê em todas as escolas" (DIRETORA-11). Outra diretora afirmou que "na minha escola não temos os materiais adequados e isso atrapalha a professora quando ela quer fazer algo diferente" (DIRETORA-14). Outra participante sinalizou que "não temos uma boa infraestrutura, equipamentos, materiais estruturados, livros, internet e outras coisas" (DIRERTOR-12). Outra profissional indicou que "a falta de infraestrutura, de parque ou quadra, atrapalha toda a proposta da professora. Isso não é só aqui, é em todas as escolas da rede" (DIRETORA-18).

Essa questão da infraestrutura, de fato, é fundamental como já sinalizaram os Referenciais Curriculares da Educação Infantil (RCNEI, 1998), pois as crianças constroem o conhecimento por meio das interações que realizam com o outro e com o meio em que estão inseridas. Tais interações acontecem nos espaços organizados (infraestrutura) e possuem enorme influência no desenvolvimento e na aprendizagem da criança.

De fato, pesquisadores sinalizaram que a "infraestrutura escolar abriga, sustenta e possibilita a criação e a organização de ambientes escolares de aprendizagem para o desenvolvimento da criança na educação infantil" (GARCIA; GARRIDO; MARCONI, 2016, p. 151). Nesse caso, a indicação das diretoras trazida neste estudo se torna ainda mais preciosa para as autoridades educacionais, que podem criar projetos para solucionar o problema da infraestrutura escolar para a Educação Física na pré-escola.

Nesse sentido, da importância da infraestrutura escolar para as aulas de Educação Física, é que as diretoras de pré-escola necessitam atuar para, constantemente, melhorar a infraestrutura da escola, visto que ela é essencial para promover a aprendizagem da criança, podendo contribuir, também, para diminuir as desigualdades sociais.

De fato, como sinalizaram Garcia, Garrido e Marconi (2016, p. 151) a infraestrutura atua no sentido de: 
econômico mais baixo (pobres) tenham acesso e oportunidades de utilizar e manusear materiais e equipamentos, e vivenciar situações de aprendizagem que não seriam possíveis em suas realidades sociais (contexto familiar e social).

Dessa forma, o esforço das diretoras de pré-escola para adquirir e melhorar a infraestrutura escolar para as aulas de Educação Física, nos três municípios analisados é, de fato, é uma forma intensa de combater as desigualdades sociais e escolares e favorecer o desenvolvimento das crianças.

\section{CONSIDERAÇões FINAIS}

Este estudo analisou a percepção de diretoras sobre os desafios e as dificuldades da prática de Educação Física na pré-escola, para o atendimento às crianças, em três municípios da região do Grande ABC. Sua realização ocorreu em uma das regiões mais ricas do Brasil.

Os elementos empíricos, sobre os desafios e as dificuldades trazidos por este estudo, revelaram, por um lado, as preocupações e o zelo das autoridades políticas e educacionais em relação à Educação Física na pré-escola, por outro, todavia, foi constatado certo descaso desses atores.

Os dados revelaram a presença de propostas curriculares específicas e muito similares, nas cidades de São Bernardo e de São Caetano, ambas construídas sobre aspectos filosóficos e epistemológicos da educação, em geral, e do desenvolvimento da criança, em particular. Uma situação que demonstra preocupações com a Educação Física na pré-escola.

As diretoras apontaram a importância da Educação Física na pré-escola, indicando, unanimemente, sua relação formativa para o desenvolvimento integral da criança nos aspectos psicomotor, cognitivo (auxilia a criança na alfabetização), afetivo e social.

Essas preocupações e zelo, todavia, eram acompanhadas de desafios e de dificuldades que eram enfrentadas no cotidiano das pré-escolas em relação, sobretudo, ao professor que ministra a aula, e no que diz respeito à formação dos profissionais e à infraestrutura escolar.

No primeiro caso, em relação ao professor, Santo André era a única cidade que dispunha, em alguns casos, do professor especialista de Educação Física atuando na pré-escola. Embora tal profissional fosse requerido pelas outras redes, nas demais cidades as aulas eram ministradas pelas professoras das salas de aula, as generalistas. Uma situação que requer reflexão, considerando que essas profissionais nem sempre apresentam formação adequada para esse trabalho.

No segundo e terceiro casos, em relação à formação de professores e à infraestrutura escolar, percebeu-se elementos de descaso das autoridades políticas e educacionais das cidades. O mais saliente estava atrelado à infraestrutura escolar. Ausência de instalações, como quadra de esportes; de materiais, como pneus e cordas; e de local adequado para aulas, foram diagnosticados neste presente estudo. Uma situação que tem ocorrido em municípios que estão entre os mais ricos do Brasil, situados na região do Grande $\mathrm{ABC}$ Paulista.

Registra-se que a ocorrência de tal descaso gera uma situação em que algumas crianças têm oportunidades de aprender nas quadras, nos parques, entre outros, enquanto outras não dispõem dessas instalações e ficam com seus direitos reduzidos. Uma situação evidente de discriminação social, que, muito provavelmente, se transformará em desigualdade escolar. 
Espera-se que com a aprovação dos Planos Municipais de Educação (aprovados em 2015 e 2016 na região), política que busca trazer avanços para a Educação, essa realidade de descaso seja transformada nos próximos dez anos. Uma situação que traria melhorias para a Educação Física na pré-escola e efeitos benéficos sobre a formação e o desenvolvimento das crianças.

\section{REFERÊNCIAS}

ALVES, N. Sobre a possibilidade e a necessidade curricular de uma Base Nacional Comum. Revista E-Curriculum, São Paulo, v. 12, n. 03, p. 1.464-1.479, out./dez. 2014.

ARANTES, A. C. Educação Física Infantil nos cursos de habilitação específica de $\mathbf{2}^{\mathbf{0}}$. grau para o Magistério em São Paulo, 1990, 302s. Dissertação (Mestrado) - Escola de Educação Física da Universidade de São Paulo, Universidade de São Paulo, São Paulo.

ÁVILA, L. T. G.; FRISON, L. M. B. Educação física na educação infantil: estratégias para promover a aprendizagem autorregulada. Revista de Educação da PUC-Campinas, Campinas, v. 17, n. 2, p. 181-189, jul./dez. 2012.

AYOUB, E. Narrando Experiências com a Educação Física na Educação infantil. Revista Brasileira de Ciências do Esporte, Campinas, v. 6, n. 3, p. 143-158, mai. 2005.

BARDIN, L. Análise de conteúdo. São Paulo: Edições 70, 1977.

BARRETO, A. M. R. Situação atual da educação infantil no Brasil. In: BRASIL. Ministério da Educação e do Desporto. Subsídios para o credenciamento e funcionamento de instituições de educação infantil, v. 2. Coordenação Geral de educação infantil. Brasília: MEC/SEF/COEDI, 1998.

BASEI, A. P. A Educação Física na educação infantil: a importância do movimentar-se e suas contribuições no desenvolvimento da criança. Revista Ibero Americana de Educação, v. 3, n. 47, 25 de outubro de 2008.

BOHME, M. T. S. Análise da Educação Física em nível pré-escolar no município de São Paulo, 1985. Dissertação (Mestrado) - Escola de Educação Física da Universidade de São Paulo, Universidade de São Paulo, São Paulo.

BRASIL. Lei de Diretrizes e Bases da Educação Nacional nº 4.024, de 20 de dezembro de 1961. Fixa as Diretrizes e Bases da Educação Nacional, Brasília, DF, dez, 1961. Disponível em: < http://www.planalto.gov.br/ccivil_03/leis/L4024.htm>. Acesso em: 14/03/2017.

BRASIL. Lei $n^{\circ} .5 .692$, de 11 de agosto de 1971. Fixa Diretrizes e Bases para o ensino de $\mathbf{1}^{\mathbf{0}}$. e $\mathbf{2}^{\mathbf{0}}$. graus, e dá outras providências, Brasília, DF, ago. 1971. Disponível em: http:// 
www2.camara.leg.br/legin/fed/lei/1970-1979/lei-5692-11-agosto-1971-357752-publicacaooriginal-1-pl.html. Acesso em: 28/05/2016.

BRASIL. Base Nacional Comum Curricular. Disponível em: http://basenacionalcomum. mec.gov.br/\#/site/inicio. Acesso em: 15/03/2017.

BRASIL. Lei nº 8.069. Estatuto da Criança e do Adolescente, Brasília, DF, 13 de julho de 1990.

BRASIL. Secretaria de Educação. Projeto de curso: habilitação ao magistério. Brasília: FEDF, 1995.

BRASIL. Lei nº 9.131, de 24 de novembro de 1995. Altera dispositivos da Lei $\mathbf{n}^{\mathbf{0}}$. 4.024, de 20 de dezembro de 1961, e dá outras providências, Brasília, DF, nov. 1995. Disponível em: http://leb.no.sapo.pt/lei_n_913195.htm. Acesso em: 04/06/2016.

BRASIL. Lei de Diretrizes e Bases da Educação Nacional nº. 9.394, de 20 de dezembro de 1996. Estabelece as diretrizes e bases da educação nacional, Brasília, DF, dez, 1996. Disponível em: http://www.planalto.gov.br/ccivil_03/leis/L9394.htm Acesso em: 28/05/2016.

BRASIL. Resolução CEB nº. 2, de 7 de abril de 1998. Institui as Diretrizes Curriculares Nacionais para o Ensino Fundamental, Brasília, DF, abr. 1998. Disponível em: http:// portal.mec.gov.br/dmdocuments/resolucao_ceb_0298.pdf. Acesso em: 04/06/2016.

BRASIL. Parecer CNE/CEB n ${ }^{\circ}$. 04, de 29 de janeiro de 1998. Diretrizes Curriculares Nacionais para o Ensino Fundamental, Brasília, DF, jan. 1998. Disponível em: http://portal. mec.gov.br/cne/arquivos/pdf/1998/pceb004_98.pdf. Acesso em: 04/06/2016.

BRASIL. Secretaria de Educação Fundamental. Parâmetros Curriculares Nacionais (5 a $8^{a}$ séries): Educação Física. Brasília: MEC/SEF, 1998.

BRASIL. Secretaria de Educação Fundamental. Referencial Curricular Nacional para Educação infantil, Conhecimento de Mundo, v. 3. Brasília: MEC/SEF, 1998.

BRASIL. Ministério da Educação. Subsídios para Credenciamento e o Funcionamento das Instituições de Educação Infantil. Brasília: MEC/SEF, 1998.

BRASIL. Secretaria de Educação Fundamental. Referencial para a Formação de Professores. Brasília: MEC/SEF, 1999.

BRASIL. Secretaria de Educação Fundamental. Parâmetros Curriculares Nacionais: Educação Física. Brasília: MEC/SEF, 2000. 
BRASIL. Ministério da Educação. Parecer CNE/CP - 009/2001. Diretrizes Curriculares Nacionais para a Formação de Professores da Educação Básica, em nível superior, curso de licenciatura, de graduação plena. Brasília, 08/05/01.

BRASIL. Ministério da Educação. Secretaria de Educação Fundamental. Parâmetros curriculares nacionais: introdução aos parâmetros curriculares nacionais, 3. ed. Brasília: SEF, 2001.

BRASIL. Resolução CEB n ${ }^{\circ}$. 01, de 31 de janeiro de 2006. Altera a alínea "b" do inciso IV do artigo $3^{\circ}$. da Resolução CNE/CEB no. 2/98, que instituiu as Diretrizes Curriculares Nacionais para o Ensino Fundamental. Brasília, DF, jan. 2006. Disponível em: http://portal.mec.gov.br/cne/arquivos/pdf/rceb001 06.pdf. Acesso em: 04/06/2016.

BRASIL. Ministério da Educação. Critérios para um Atendimento em Creches que Respeite os Direitos Fundamentais das Crianças, 2. ed. Brasília: Secretaria de Educação Básica, 2009.

BRASIL. Constituição da República Federativa do Brasil, 35. ed. Brasília: Edições Câmara, 2012.

BRASIL. Ministério da Educação. Secretaria de Educação Básica. Diretoria de Currículos e Educação Integral. Diretrizes curriculares nacionais gerais da educação básica. Brasília: MEC, SEB, DICEI, 2013.

BRASIL. INSTITUTO NACIONAL DE ESTUDOS E PESQUISAS EDUCACIONAIS. Censo Educacional. Brasília: INEP, 2015.

BRASIL. Lei no ${ }^{\circ}$ 13.005, de 25 de junho de 2014. Plano Nacional de Educação, PNE, Brasília, DF, jun. 2014. Disponível em: http://www.planalto.gov.br/ccivil_03/_ato20112014/2014/lei/113005.htm. Acesso em: 05/06/2016.

CERSÓSIMO, R.; SATO, K. A criança e a educação física. In: GONSALVES, P. (Org.). Tudo sobre a criança: perguntas e respostas. São Paulo: IBRASA, 2003.

D'AVILA, A. S. Educação Física na educação infantil: o papel do professor de Educação Física, 2016. Monografia (Licenciatura). Escola de Educação Física, Universidade Federal do Rio Grande do Sul, Rio Grande do Sul.

FERRAZ, O. L. Educação Física na Educação Infantil e o Referencial Curricular Nacional: o significado para os professores, 2000. Tese (Doutorado). Faculdade de Educação da Universidade de São Paulo, Universidade de São Paulo, São Paulo.

FERRAZ, O. L.; MACEDO, L. Reflexões de professores sobre a Educação Física na educação infantil incluindo o referencial curricular nacional. Revista Paulista de Educação Física, São Paulo, v. 15, n. 1, p. 83-102, jan./jun. 2001. 
FLICK, U. Introdução à Metodologia de Pesquisa: Um Guia Para Iniciantes. São Paulo: Penso, 2012.

FRANCO, M. A. Pedagogia e prática docente. São Paulo: Cortez Editora, 2012.

FREIRE, J. B. Educação de Corpo Inteiro: teoria e prática da Educação Física. São Paulo: Scipione, 1997.

GAllAHUE, D.; DONNELLY, F. Educação Física Desenvolvimentista para todas as crianças, 4. ed. São Paulo: Phorte, 2008.

GALLAHUE, D.; OZMUN, J. Compreendendo o desenvolvimento motor: bebês, crianças, adolescentes e adultos. São Paulo: Phorte, 2005.

GALLARDO, J. S. P. Delimitando os conteúdos da cultura corporal que correspondem à área de Educação Física. Conexões (UNICAMP), Campinas, v. 1, n. 1, p. 34-54, 2003.

GARCIA, P. S. Inovações e Mudanças: por que elas não acontecem nas escolas? Uma macroanálise envolvendo professores de Ciências, 1. ed. São Paulo: LCTE Editora, 2010.

GARCIA, P. S.; PREARO, L. C.; ROMEIRO, M. C.; BASSI, M. S. Diretores de escola e gestão democrática na região do $\mathrm{ABC}$ Paulista. Política e Gestão Educacional, v. 1, p. $87-107,2016$.

GARCIA, P. S.; GARRIDO, E. L.; MARCONI, J. UM estudo sobre a infraestrutura da educação infantil da região do grande ABC Paulista. Holos, v. 1, p. 139-154, 2017.

GIL, A. C. Como elaborar projetos de pesquisa, 4. ed. São Paulo: Editora Atlas, 2002.

GODOY, A. S. Introdução à Pesquisa Qualitativa e Suas Possibilidades. Revista de Administração e Empresas, São Paulo, v. 35, n. 2, p. 57-63, mar./abr. 1995.

GONZÁLEZ, F. J.; FRAGA, A. Referencial Curricular de Educação Física. In:

RIO GRANDE DO SUL. Secretaria de Estado de Educação. Departamento Pedagógico.

(Org.). Referências Curriculares do Estado do Rio Grande do Sul: Linguagens,

Códigos e suas Tecnologias, 1. ed. Porto Alegre: SE/DP, 2009, v. 2, p. 112-181.

GRABER, K.; WOODS, A. Educação Física e Atividades para o Ensino Fundamental. Porto Alegre: Mcgraw-Hill Education, 2014.

KUNZ, E. Didática da Educação Física, 2. ed. Ijuí: Unijuí, 2001.

LEITE, Y. U. F. Pesquisa-ação como espaço de formação de professores: análise de uma experiência vivida. In: Selma Garrido Pimenta; Maria Amélia Santoro Fonseca (Org.). Pes- 
quisa em educação: possibilidades investigativas/formativas da pesquisa-ação, 1. ed. São Paulo: Edições Loyola, 2008.

LEONE, N. M.; LEITE, Y. U. F. O início da carreira docente: implicações à formação inicial de professores. Revista Eletrônica Pesquiseduca, Santos, v. 3, n. 6, p. 236-259, jul./ dez.2011.

MAGALHÃES, J. S., KOBAL, M. C., GODOY, R. P. Educação Física na educação infantil: uma parceria necessária. Revista Mackenzie de Educação Física e Esporte, v. 6, n. 3, p. 43-52, 2007.

MELLO, M.A. Educação Infantil e Educação Física: um binômio separado pelo movimento, mas qual o movimento? Disponível em: http://ambientedetestes2.tempsite.ws/ ciencia-para-educacao/publicacao/mello-educacao-infantil-e-educacao-fisica-um-binomio-separado-pelo-movimento-mas-qual-movimento-in-23a-reuniao-anual-da-associacao-nacional-de-pos-graduacao-e-pesquisa-em-educacao-anped-2000/. Acesso em: 23/04/2018.

NEIRA, M. G. Alternativas existem! Análise da produção científica em dois periódicos brasileiros sobre a docência em Educação Física. Movimento (UFRGS. Impresso), Porto Alegre, v. 18, p. 241-257, 2012.

NEVES, J. L. Pesquisa Qualitativa: Características, Usos e Possibilidades. Caderno de Pesquisas em Administração, São Paulo, v. 1, n. 3, 1996.

ODGABC - OBSERVATÓRIO DE EDUCAÇÃO DO GRANDE ABC, 2015. Disponível em: http://www.uscs.edu.br/sites/oegabc/o-observatorio.html. Acesso em: 02/02/2018.

PAIXÃO, J. A.; BARROSO, Y. W.; CUSTÓDIO, G. C. Formação do professor de educação física e as dificuldades no início de carreira em escolas de ensino básico. Horizontes, Itatiba, v. 34, n. 2, p. 57-68, ago./dez. 2016.

PIMENTA, S. G. Pedagogia como campo de conhecimento: dimensões construtivas. Educação em Foco, Belo Horizonte, v. 17, p. 38-55, 2011.

PREFEITURA MUNICIPAL DE FLORIANÓPOLIS. A Educação Física Na Educação Infantil Da Rede Municipal De Ensino De Florianópolis. Florianópolis: Secretaria Municipal de Educação, 2016.

ROLIM, L. R. O professor de Educação Física na educação infantil: uma revisão bibliográfica, 2004. Dissertação (Mestrado). Centro Universitário Nove de Julho - UNINOVE, São Paulo. 
SÃO BERNARDO DO CAMPO. Proposta Curricular - Educação Infantil, v. 2, c. 2. Secretaria de Educação e Cultura Departamento de Ações Educacionais, 2007.

SÃO CAETANO DO SUL. Orientações Curriculares - Educação Infantil. Secretaria Municipal de Educação, 2013.

SILVA, O. O. N. Licenciatura e Bacharelado em Educação Física: diferenças e semelhanças. Revista Espaço Acadêmico, Maringá, v. 1, n. 124, p. 76-84, set. 2011.

TRIVIÑOS, Augusto. Introdução à pesquisa em ciências sociais: a pesquisa qualitativa em educação. São Paulo: Atlas, 1987.

VIEIRA, M. S. Por uma Educação Física com sabor: possibilidades e desafios no ensino infantil. In: XV CONGRESSO BRASILEIRO DE CIÊNCIAS DO ESPORTE E II CONGRESSO INTERNACIONAL DE CIÊNCIAS DO ESPORTE. Anais eletrônicos. Recife: CBCE, 2007.

VOKOY, T.; PEDROZA, R. Psicologia Escolar em educação infantil: reflexões de uma atuação. Psicologia Escolar Educação (On-line), v. 9, n. 1, p. 95-104, 2005. Disponível: www.uscs.edu.br/sites/oegabc/escolas-do-grande-abc.html. Acesso em 13/05/2018.

\section{DADOS DOS AUTORES:}

\section{Alex Moura Sobrinho}

Mestre em Educação. Professor de Educação Física na rede educacional dos municípios de São Caetano do Sul e Santo André. São Paulo/SP-Brasil. alexsobri@hotmail.com

\section{Paulo Sergio Garcia}

Professor do Programa de Pós-Graduação da Universidade Municipal de São Caetano do Sul. São Caetano do Sul/SP-Brasil. garcia@uscs.edu.br

Submetido em: 23-5-2019

Aceito em: 16-1-2020 